\title{
A case of Chiari network and paradoxical emboli
}

\author{
Seyed T Moradian and Seyed MS Ghiasi* \\ Atherosclerosis Research Center, Baqiyatallah University of medical sciences, Tehran, Iran
}

\begin{abstract}
Chiari network is an anatomic variant that is present in minority of population and usually is described clinically non-significant. Many of patients with chiari network have patent foramen ovale (PFO). We present a case of young women with chiari network, patent foramen ovale, and cerebrovascular accident due to paradoxical emboli.
\end{abstract}

\section{Introduction}

Chiari network is a normal variant anatomic structure that is possible to be derived from sinus venous [1]. It is a mobile, thin, weblike structure that may be seen in $2 \%$ of echocardiographs [2]. This structure is benign, but in many cases a simultaneous patent foramen ovale and right to left shunting is there [3]. In most articles there is no pathological role for Chiari network, but some studies have linked Chiari network with various complications [4]. Presence of the Chiari network and patent foramen ovale may enhance the formation of an atrial septal aneurysm and facilitate paradoxical embolism $[3,5]$. The role of Chiari network in thrombosis formation is not well defined.

\section{Case report}

A 38 years age old women with a history of three months ago ischemic cerebrovascular accident was referred to the cardiac clinic. In physical examination patient had right side paresthesia. Eechocardiography was performed due to the lack of risk factors for thrombosis. Transthoracic echocardiography revealed a large PFO and Chiari network, requiring surgery. Other structures were normal and heart function was acceptable. The electrocardiography showed a sinus rhythm. Patient doesn't have the history of atrial fibrillation and coagulation disorders, deep vein thrombosis or pulmonary emboli. Surgery was done using the cardiopulmonary bypass. The right atrium was incised and PFO was evaluated. The defect was repaired using a simple whip stitch of continuous prolane.

\section{Discussion}

Chiari network has been reported in $2-3 \%$ of population [2]. It has no clinical significance and does not cause any clinical symptom. It usually is diagnosed incidentally [6,7]. Despite the fact that in itself is not important, but its presence is associated with a great range of symptoms. Several disturbances such as PFO, paradoxical emboli, clot formation, infective endocarditis, heart failure, and supraventricular arrhythmia are reported [5,8-11]. Also preventing from right atrium catheter implantation, pace wire lead insertion and $\mathrm{CPB}$ cannulation are related to Chiari network [12-14]. In thrombophilia it acts such as inferior vena cava filter and prevents emboli [15].

In recent years, using the three-dimensional echocardiography it is more likely to distinguish it from other disorders [16]. Disorders such as right atrium thrombosis, tumour and vegetation cause diagnostic confusion [7,17]. In this patient, the wrong diagnosis was performed using echocardiography twice as a thrombosis.

Simultaneous PFO is reported in more than $80 \%$ of patients [11]. In the presence of PFO the risk of paradoxical emboli and ischemic stroke is increased [18]. Of course, PFO without the presence of Chiari network is a risk factor for embolism. So, we do not know what percentage of the risk is related to the simultaneous presence of Chiari network. In some studies, has been said that Chiari network can be a source of clot formation. Also, some studies report cases of patients suffering a paradoxical embolism without patent foramen ovale [19].

The detailed indications for Chiari network surgery are not clear. Chiari network usually does not require independent surgery, but if a patient is undergoing cardiac surgery for other reasons the Chiari network will be removed [11]. In patients suspected of having paradox emboli indications for surgery is not specified.

In conclusion, Chiari network as a common finding should be considered in the differential diagnosis. Although the paradoxical embolism following Chiari network is uncommon, the characteristics of the Chiari network described here might explain the pathophysiology of a paradoxical embolism [4]. Also, how to deal with Chiari network is controversial. Chiari network by itself is not pathological findings, but the complications associated with it can be challenging.

\section{References}

1. Jansirani DD, Deep SS, Anandaraja S (2015) Anatomical Study of Chiari Network and the Remnant of Left Venous Valve in the Interior of Right Atrium. Anat Res Int 2015; 2015. [Crossref]

2. Bhatnagar KP, Nettleton G, Campbell FR, Wagner CE, Kuwabara N, et al. (2006) Chiari anomalies in the human right atrium. Clin Anat 19: 510-516. [Crossref]

3. Schneider B, Hofmann T, Justen MH, Meinertz T (1995) Chiari's network: normal anatomic variant or risk factor for arterial embolic events? J Am Coll Cardiol 26: 203210. [Crossref]

*Correspondence to: Seyed Mohammad Saeid Ghiasi, Baqiyatallah University of medical sciences, Tehran, Iran, Tel: 09123781448, E-mail: T.moradyan@yahoo.com

Key words: chiari network, echocardiography, paradoxical emboli

Received: December 06, 2018; Accepted: December 18, 2018; Published: December 21, 2018 
4. Joseph L, Ward C, Alqasrawi M, Marthaler B, Shewmake A, et al. (2015) Echocardiographic Diagnosis of Chiari Network and Arterial Embolic Events. Circulation 132: A19214

5. Schwimmer-Okike N, Niebuhr J, Schramek GG, Frantz S, Kielstein H (2016) The Presence of a Large Chiari Network in a Patient with Atrial Fibrillation and Stroke. Case Rep Cardiol 2016: 4839315. [Crossref]

6. Poanta L, Albu A, Fodor D (2010) Chiari network-case report and brief literature review. Med Ultrason 12: 71-72. [Crossref]

7. Islam AK, Sayami LA, Zaman S (2013) Chiari network: A case report and brief overview. J Saudi Heart Assoc 25: 225-229. [Crossref]

8. Mousavi N, Bhagirath K, Ariyarajah V, Fang T, Ahmadie R, et al. (2008) Chiari network endocarditis: not just an innocent bystander. Echocardiography 25: 642-645. [Crossref]

9. Dregoesc D, Rejent M, Zhang A, Abousy R (2013) Incidental Discovery of Chiari Network in a Patient with New Onset of Atrial Fibrillation. J Clin Case Rep 4: 2.

10. Ward C, Joseph L, Doshi H, Alkasrawi m, Marthaler B, et al. (2016) Atrial septal aneurysm and chiari network are not innocent bystanders: association with cardiomyopathy, cardiac conduction abnormalities, and arrhythmias exist. $J \mathrm{Am} \mathrm{Coll}$ Cardiol 67: 1324

11. Laguna G, Arce N, Blanco M (2015) Giant Chiari network, foramen ovale, and paradoxical embolism. Rev Esp Cardiol (Engl Ed) 68: 250. [Crossref]
12. Sakamoto A, Urushida T, Sakakibara T, Sano M, Suwa K, et al. (2016) Accidental Entrapment of Electrical Mapping Catheter by Chiari Network in Right Atrium during Catheter Ablation Procedure. Case Reports in Cardiology 2016; 2016.

13. Aung H, Espinosa RE, Powell BD, Mcleod CJ (2016) Entrapment of a Pacing Lead within a Chiari Network: Utility of Intracardiac Echo and a Laser Sheath. Pacing Clin Electrophysiol 39: 620-622. [Crossref]

14. Teo EY, Ittleman F, Hamlin MP (2010) A Chiari network and difficult cannulation of the coronary sinus for retrograde perfusion. Anesth Analg 111: 79-81. [Crossref]

15. Obaji SG, Cooper R, Somauroo J (2012) Chiari network: a protective filter against pulmonary embolism in a case of polycythaemia. BMJ Case Rep 2012: bcr0520114289. [Crossref]

16. Pothineni KR, Nanda NC, Burri MV, Singh A, Panwar SR, et al. (2007) Live/Rea Time Three-Dimensional Transthoracic Echocardiographic Visualization of Chiari Network. Echocardiography 24: 995-997. [Crossref]

17. Walpot J, Sahin-Arpaci G, Sadreddini M (2015) A chiari network mimicking a cystic structure. Neth Heart J 23: 70-71. [Crossref]

18. Overell JR, Bone I, Lees KR (2000) Interatrial septal abnormalities and stroke: a metaanalysis of case-control studies. Neurology 55: 1172-1179. [Crossref]

19. Pearson AC, Nagelhout D, Castello R, Gomez CR, Labovitz AJ (1991) Atria septal aneurysm and stroke: a transesophageal echocardiographic study. $\mathrm{J} \mathrm{Am} \mathrm{Coll}$ Cardiol 18: 1223-1229. [Crossref]

Copyright: (C2018 Moradian ST. This is an open-access article distributed under the terms of the Creative Commons Attribution License, which permits unrestricted use, distribution, and reproduction in any medium, provided the original author and source are credited. 